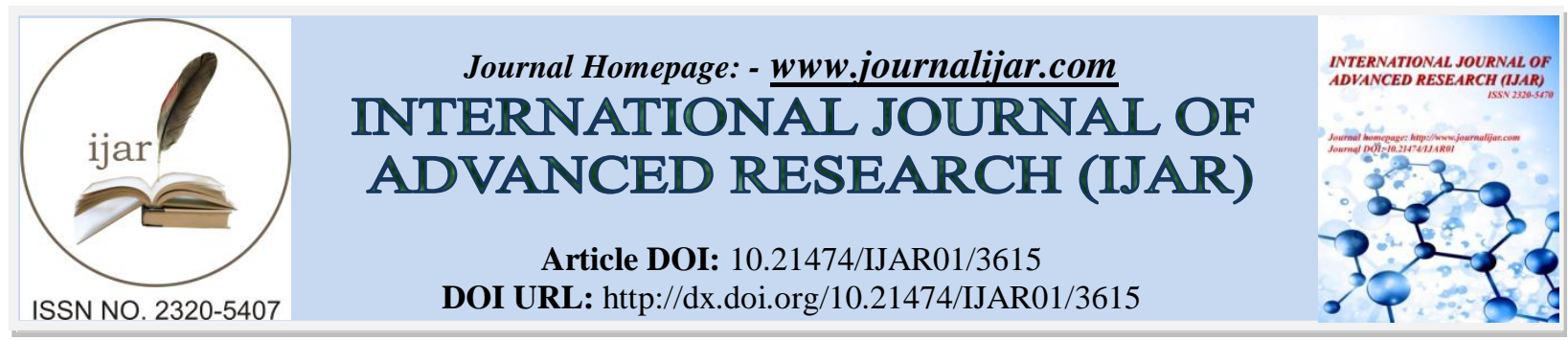

RESEARCH ARTICLE

\title{
A COMPARATIVE STUDY ON INTERNET USE BY RURAL AND URBAN COLLEGE STUDENTS.
}

Tapas Karmakar ${ }^{1}$ and Manas Karmakar ${ }^{2}$.

1. Lecturer, Department of Education, Nistarini College, Purulia, West Bengal India

2. Student, Manbhum B.Ed. College, Purulia, West Bengal India

\section{Manuscript Info}

Manuscript History

Received: 07 January 2017

Final Accepted: 14 February 2017

Published: March 2017

Key words:-

Internet, Gender, Residence, Religion,

Stream (Science, Arts).

\begin{abstract}
This world is termed science and technology. Using digital devices could be a vast part of their everyday expertise. In each facet of life, we have a tendency to use technology. Technology creates our life quicker, better and easier. With the assistance of technology, we are able to simply create the teaching-learning method softer and on the market. There's no facet of human life that isn't bitten by technology. Numerous technologies have been employed in education, the internet is one in every of them. The Internet is that the backbone of this society. The Internet plays a very important role in developing the communication or interaction method. Present days is that the world of web or internet. The Internet has created our lives batter. Through the internet, we are able to simply communicate with our knowledgeable or guide everywhere in the planet. It's true that the employment of internet in rural and urban areas is increasing day by day. This study was conducted to compare the use of the internet by rural and urban college students. The sample consists of 150 female and 150 male students from four colleges in Purulia district, West Bengal, India selected randomly. The study revealed that urban college students use the internet quite rural college students in terms of daily or $3 / 4$ times of every week as calculated criteria. Once analysis it's additionally found that male college students use internet quite the feminine college students in terms of daily or $3 / 4$ times of every week. The present study also indicates that Science college students use internet over the arts college students in terms of daily or $3 / 4$ times of every week. However, the humanities college students use the internet over science counterpart in terms of $3 / 4$ times of a month or at least one time of a month. Gift study additionally indicates that Hindu college students use the internet quite Muslim college students in terms of daily or $3 / 4$ times of every week and a lot of students use internet for the purpose of social media and news.
\end{abstract}

Copy Right, IJAR, 2017,. All rights reserved.

Corresponding Author:- Tapas Karmakar. 


\section{Introduction:-}

Internet is one of the powerful parts of technology and also essential for whole human society. Internet provides $24 / 7$ access information at one click. Today without internet we can't think about our daily life. Internet is the core part of education system. Today more people are on the internet than anywhere else. With over 460 million internet users, India is the second largest online market, ranked only behind China. By 2021, there will be about 635.8 million internet users in India. Despite the large base of internet users in India, only 34.8 percent of the Indian population accessed the internet in 2016. This is a significant increase in comparison to the previous years, considering the internet penetration rate in India stood at about 10 percent in 2011. Furthermore, men dominated internet usage in India with 71 percent to women's 29 percent (www.statista.com/topics/2157/internet-usage-inindia). At present, the study noted, rural Indians use the Internet mainly for social network websites (around $70 \%$ of the Internet users living in rural areas) such as Facebook, and for emailing. A report titled 'Internet in India 2016' by the Internet and Mobile Association of India (IAMAI) jointly published by the IMRB, mentions that the number of internet users in India is expected to reach between 450-465 million by June 2017. It adds that the country had 432 million mobile internet users in December 2016, of which 269 million or $62.3 \%$ were from urban India and 163 million, or 37.7\% were from rural India (Pai, 2017, http://www.medianama.com/author/vivek/).

Internet used in India (Figures by Millions)

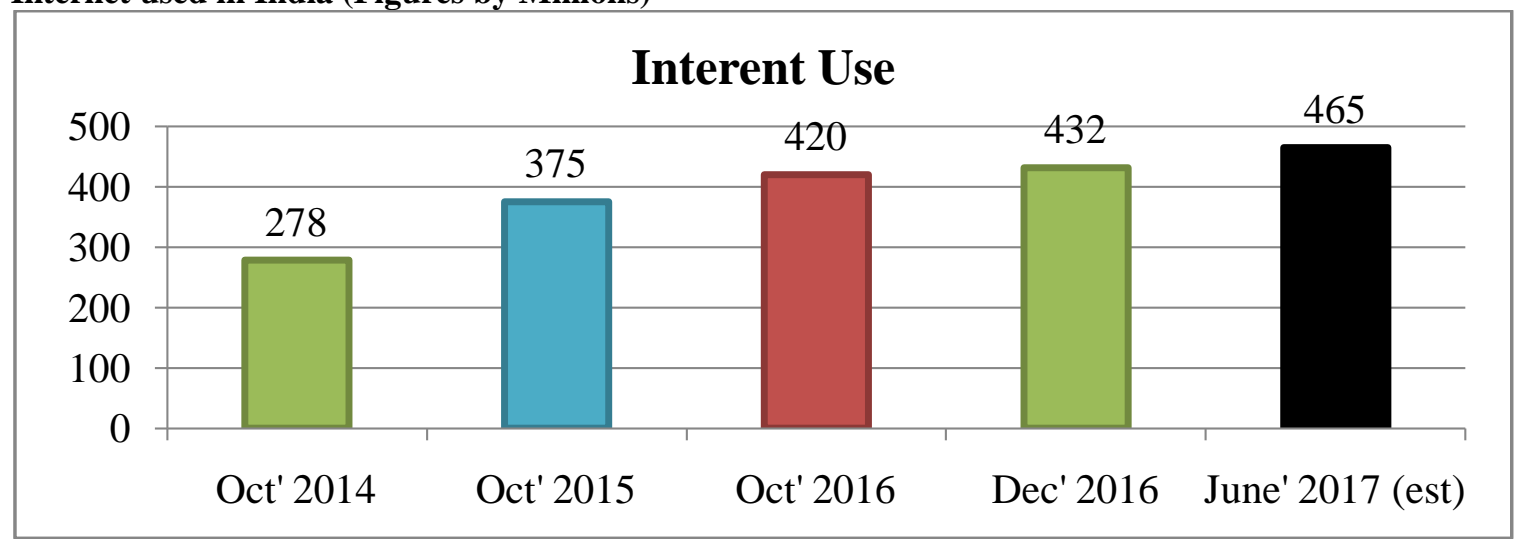

Source: IMRB 1-cube.

By gender, $40 \%$ of daily internet users from urban areas consisted of females, where only $25 \%$ of daily internets users from rural areas are were females.

Today the use of internet is the common matter in India. It is assumed that the college students in India feel more dependent on the Internet for their class assignments and for the latest information about their subject areas than conventional resources of information. A good number of the youth particularly college students use the internet for social interaction and communication as well as for their education. But, just as they use the internet to take help of their education, they use social sites to enrich their social lives (Jones, 2002). College also feels a bit handicapped in updating their knowledge base quickly without using the Internet for their research and classroom teaching activities (Sridevi \& Indrani, 2015). Internet came to India in early 1990 for a restricted group of users only. But, now it is open to everyone (Singh, 2014). Jackson, et al. (2011) remarked that the Internet would increase the educational level due to its reach and availability to everyone, everywhere and anytime. The internet has created the opportunities for people of all ages of students to contribute and access information.

\section{Definition of Internet:-}

Cambridge International Dictionary of English defines Internet as "large system of many connected computers around the world which people use to communicate with each other". (Network of networks) The internet knowledge is the knowledge of the basic theoretical aspects of the internal and its practical application. According to Douglas E. Comer (2003) internet is "the collection of networks and routers that use the TCP/IP protocol suite and function as a single, large network. The internet reaches government, commercial and educational organization around the world. 


\section{Statement of the Problem:-}

The problem for the present study is specifically stated as below:

A Comparative Study on Internet Use by Rural and Urban College Students.

\section{Literature Review:-}

Bimber, B. (2000) after measuring the differences in men's and women's use of the Internet in U.S. found the existence of gender gap in their Internet use. Ono, H. \& Zavodny, M. (2003) also found women to be less frequent and less intense users of the Internet. Concern about gender inequality has now shifted from access to intensity. Mishra, O.P., Yadava, N. \& Bisht, K. (2005) conducted a research study to learn the Internet utilization patterns of undergraduate students at the G B Pant University of Agriculture and Technology. The findings of the study revealed that a majority of the students $(85.7 \%)$ used the Internet in which male students use Internet in greater numbers than females. Kumar, R. \& Kaur, A. (2005) disclosed that majority of the respondents $(69.4 \%)$ used the internet for educational purpose, $(51.9 \%)$ for research purpose, $(47.4 \%)$ for communication purpose and $34.7 \%$ for entertainment purpose. Mishra, et al. (2005) indicated that a majority of the students $(85.7 \%)$ use internet in which that male students are more than female students. Loan, A.F. (2011) revealed that majority of the students are frequent users of internet using internet from daily to week basis in which use by urban students is more than their rural counterparts. Thanuskodi, S. (2013) found that internet was used by boys and girls to some extent. Both boys and girls had equal access to Internet but there was a difference in usage pattern. Sharma, et.al. (2014) conducted a survey on 391 and found that male's students were more addicted to the internet use than female.

\section{Delimitations of the Study:-}

\section{(A) Geographical Area}

The investigation was delimited to only Purulia district of West Bengal India.

\section{(B) Level of Education}

1. The study was restricted to the college students (UG level) in Purulia district.

2. Among the College students, only the science and Social Science students were considered as the subjects of the present study.

\section{Objectives of the Study:-}

The study was conducted to find out the following objectives.

1. To point out the frequency of the internet use by college students

2. To compare the use of internet by rural and urban college students.

3. To compare between Male and Female college students in respect of their using internet.

4. To compare between Arts and Science college students in respect of their using internet.

5. To compare between Hindu and Muslim college students in respect of their using internet.

6. To know the purpose of internet use.

\section{Methodology of the Study:-}

The survey method of research was used to conduct the study and a structured questionnaire, specially drafted for the purpose is used for collecting the data. Data ware analyzed by different quantitative techniques and presented in the appropriate formats.

\section{Population of the Study:-}

All the college students (UG level) in Purulia district of West Bengal (India) are the population of this study.

\section{Sample and Sampling:-}

Four Colleges of Purulia district, West Bengal were selected randomly. The researchers selected 300 students randomly. Here stratified random sampling technique was adopted. The sample profile is given in Table- 1 .

Table 1:- Sample Profile.

\begin{tabular}{|l|l|l|l|l|l|l|l|}
\hline Male & Female & Rural & Urban & Science & Arts & Hindu & Muslim \\
\hline 150 & 150 & $130 \quad 170$ & 100 & 200 & 260 & 40 \\
\hline \multicolumn{2}{|c|}{ Total 300 } & \multicolumn{2}{|c|}{ Total 300 300 } & \multicolumn{2}{c|}{ Total 300 } \\
\hline
\end{tabular}




\section{Data Analysis and Discussion:-}

In this chapter, the researchers analyzed and interpreted the data collected. The data are collected through questionnaire method. After checking the questionnaire for completion and editing the entire, the researchers analyzed the data.

Objective-1: To point out the frequency of use internet by college students.

Table 2:- Show the frequency of use internet by college students

\begin{tabular}{|c|c|}
\hline Use Internet & College Students \\
\hline Daily & $100 / 300(33.33 \%)$ \\
\hline 3/4 Times of every week & $120 / 300(40 \%)$ \\
\hline 3/4 Times of a month & $60 / 300(20 \%)$ \\
\hline One time of a month & $20 / 300(6.67 \%)$ \\
\hline
\end{tabular}

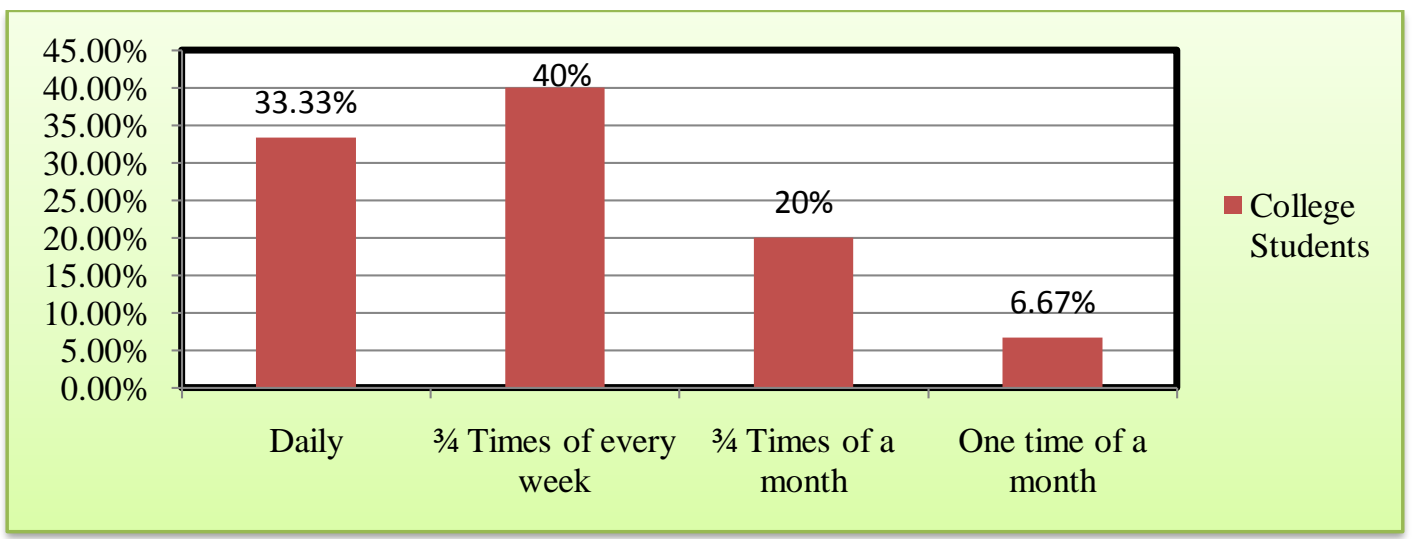

Figure 1:- Percentage of using internet by college students.

Table 2 shows that 73.33 percentage college students using internet from daily to $3 / 4$ times of every week and 26.67 percentage college students using internet from $3 / 4$ times of a month to at least one time of a month.

Objective 2:- To Compare the use of internet by rural and urban college students.

Table 3:- Show use of internet by rural and urban college students

\begin{tabular}{|c|c|c|}
\hline Use Internet & Rural & Urban \\
\hline Daily & $55 / 130(42.31 \%)$ & $80 / 170(47.06 \%)$ \\
\hline 3/4 Times of every week & $45 / 130(35.62 \%)$ & $65 / 170(38.24 \%)$ \\
\hline 3/4 Times of a month & $20 / 130(15.38 \%)$ & $15 / 170(8.82 \%)$ \\
\hline One time of a month & $10 / 130(7.69 \%)$ & $10 / 170(5.88 \%)$ \\
\hline
\end{tabular}

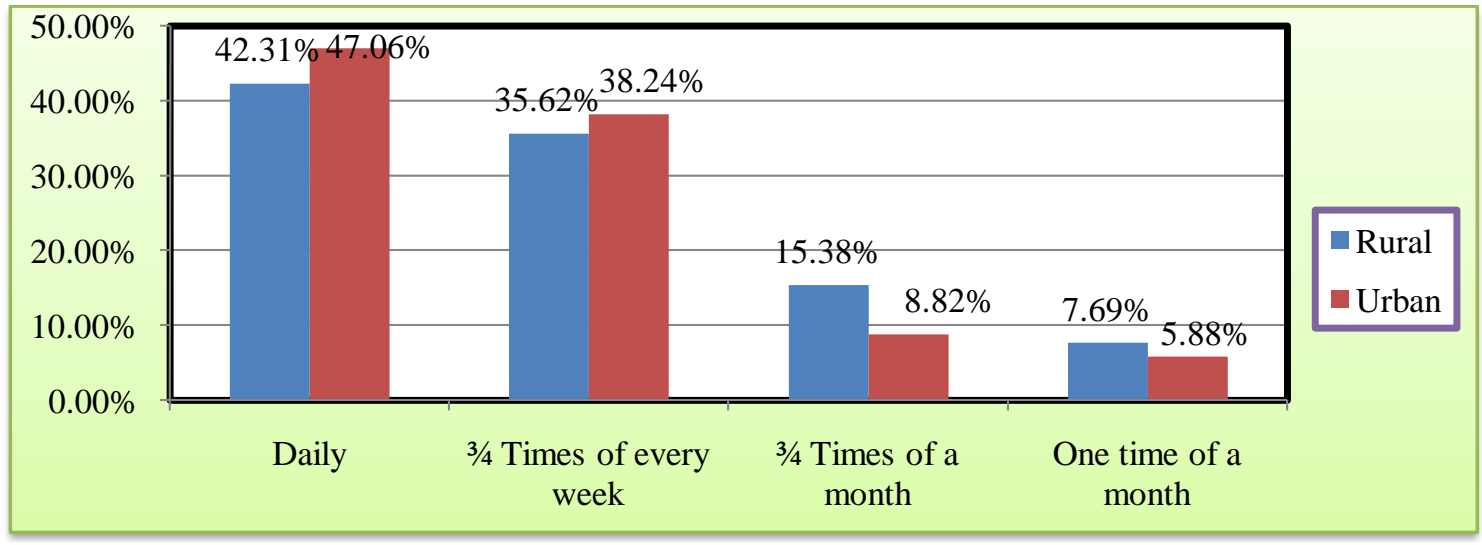

Figure 2:- Percentage of using internet by rural \& urban college students. 
Table- 3 shows area wise using internet. It's noted that 77.93 percentages rural college students using internet starting from daily to $3 / 4$ times of every week. Whereas 85.3 percentages urban college students using internet starting from daily to $3 / 4$ times of every week. On the opposite hand it's noted that 23.07 percentages rural college students using internet starting from $3 / 4$ times of a month to at least one time of a month compared to 14.7 percentages of urban college students.

Objective-3: To compare between male and female students in respect of their using internet.

Table 4:- Show internet using by male and female college students

\begin{tabular}{|c|c|c|}
\hline Use Internet & Male & Female \\
\hline Daily & $90 / 150(60 \%)$ & $40 / 150(26.67 \%)$ \\
\hline 3/4 Times of every week & $30 / 150(20 \%)$ & $70 / 150(46.67 \%)$ \\
\hline 3/4 Times of a month & $20 / 150(13.33 \%)$ & $30 / 150(20 \%)$ \\
\hline One time of a month & $10 / 150(6.67 \%)$ & $10 / 150(6.67 \%)$ \\
\hline
\end{tabular}

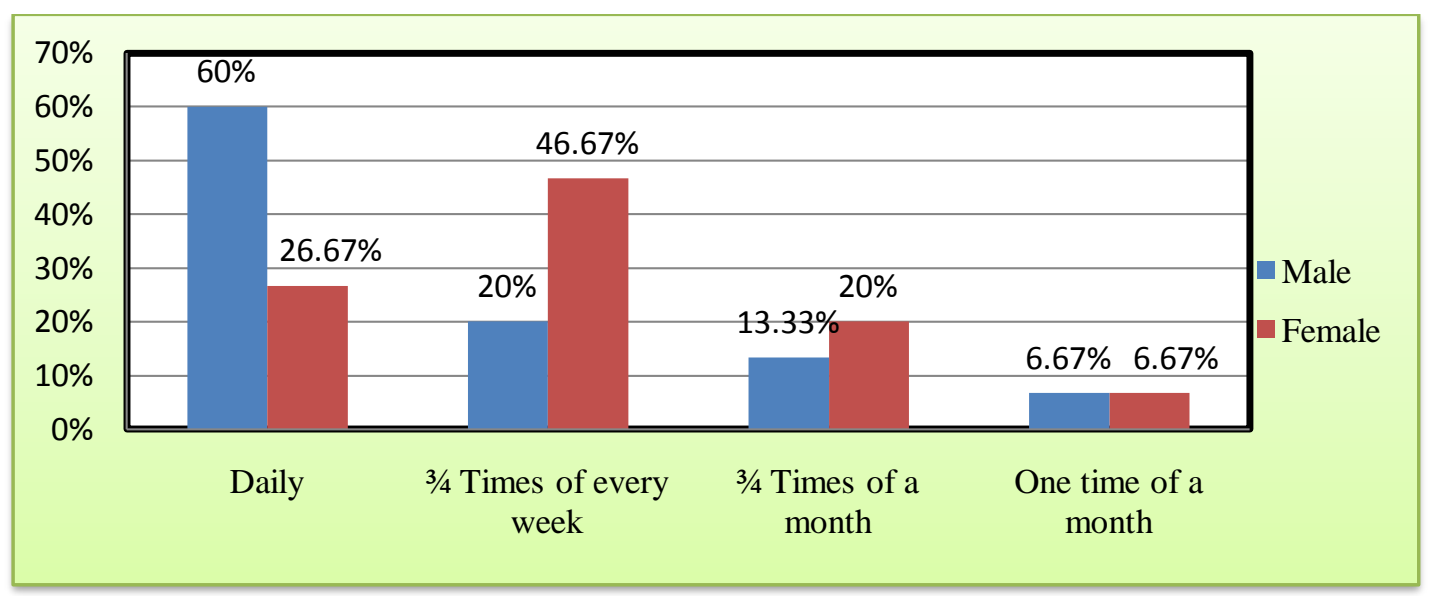

Figure 3:- Percentage of using internet by male \& female college students

Table- 4 shows gender wise using internet. It's noted that 80 percentages male college students using internet ranging from daily to $3 / 4$ times of every week. Whereas 73.34 percentages female college students using internet ranging from daily to $3 / 4$ times of every week. On the other side it's noted that 20 percentages male college students using internet ranging from $3 / 4$ times of a month to at least one time of a month compared to 26.67 percentages of female college students.

Objective 4:- To compare between arts, science students in respect of their using internet.

Table 5:- Show using internet by Arts and Science college students

\begin{tabular}{|c|c|c|}
\hline Use Internet & Arts & Science \\
\hline Daily & $90 / 200(45 \%)$ & $70 / 100(70 \%)$ \\
\hline 3/4 Times of every week & $70 / 200(35 \%)$ & $20 / 100(20 \%)$ \\
\hline 3/4 Times of a month & $35 / 200(17.05)$ & $10 / 100(10 \%)$ \\
\hline One time of a month & $10 / 200(5 \%)$ & $00 / 100(0 \%)$ \\
\hline
\end{tabular}




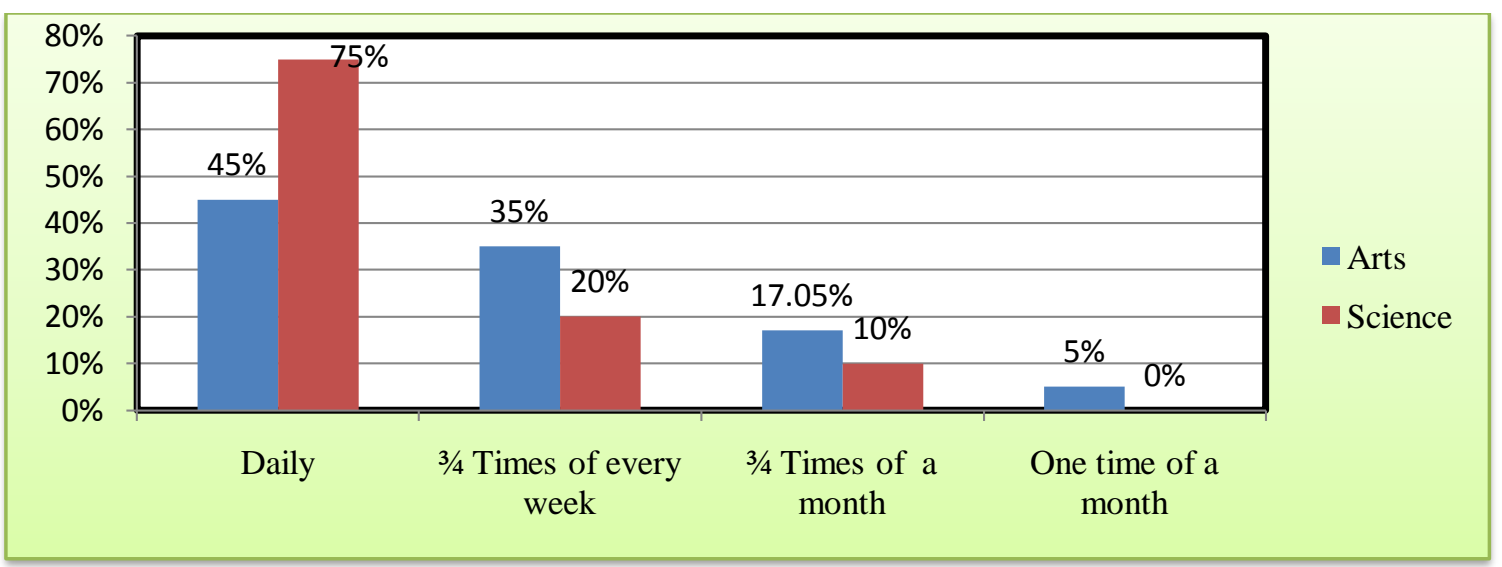

Figure 4:- Percentage of using internet by arts \& science college students.

Table- 5 shows stream (Arts \& Science) wise using internet. It's noted that 80 percentages arts college students using internet ranging from daily to $3 / 4$ times of every week. Whereas $90 \%$ percentages science college students using internet ranging from daily to $3 / 4$ times of a week. On the other side it's noted that 22.05 percentages arts college students using internet ranging from $3 / 4$ times of a month to at least one time of a month compared to 10 percentages of science college students.

Objective 5:- To Compare between Hindu and Muslim college students in respect of their using internet.

Table 6:- Show using internet by Hindu and Muslim college students

\begin{tabular}{|c|c|c|}
\hline Use Internet & Hindu & Muslim \\
\hline Daily & $140 / 260(53.85 \%)$ & $10 / 40(25 \%)$ \\
\hline 3/4 Times of every week & $60 / 260(23.08 \%)$ & $20 / 40(50 \%)$ \\
\hline 3/4 Times of a month & $40 / 260(15.38 \%)$ & $5 / 40(12.5 \%)$ \\
\hline One time of a month & $20 / 260(7.69 \%)$ & $5 / 40(12.5 \%)$ \\
\hline
\end{tabular}

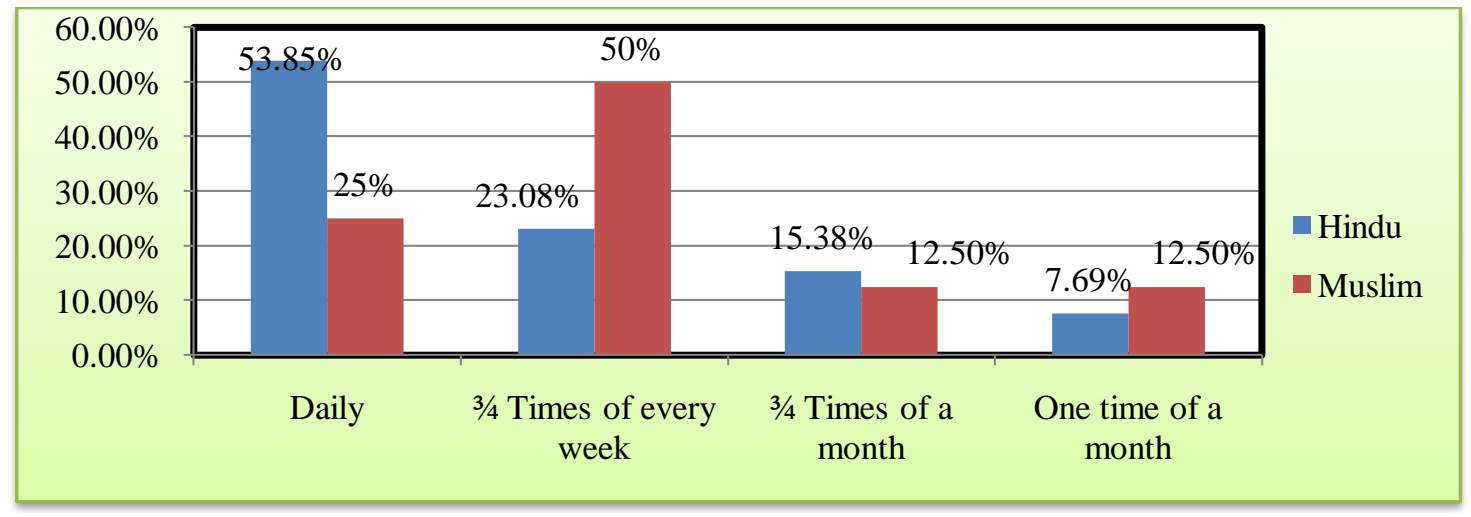

Figure 5:- Percentages of using internet by Hindu \& Muslim college students.

Table- 6 shows religious (Hindu \& Muslim) wise using internet. It's noted that 76.93 percentages Hindu college students using internet ranging from daily to $3 / 4$ times of every week. Whereas 75 percentages Muslim college students using internet ranging from daily to $3 / 4$ times of every week. On the other hand it's noted that 23.07 percentages Hindu college students using internet ranging from $3 / 4$ times of a month to at least one time of a month compared to 25 percentages of Muslim college students. 
Objective 6:- To know the purpose of internet use.

Table 7:- purpose of internet using by college students

\begin{tabular}{|c|c|}
\hline Purpose of Internet Use & Total \\
\hline Educational Information & $62 / 300(20.67 \%)$ \\
\hline Social Media and News & $150 / 300(50 \%)$ \\
\hline Audios and Videos & $38 / 300(12.67 \%)$ \\
\hline Gaming & $30 / 300(10 \%)$ \\
\hline Other & $20 / 300(6.67 \%)$ \\
\hline
\end{tabular}

From the table-7 it's clear that the college students used internet primarily social media and news (50\%) followed by educational information (20.67\%), audios and videos (12.67\%), gaming (10\%) and a small number of students used internet for other purpose like online shopping or searching $(6.67 \%)$.

\section{Conclusion:-}

Present study indicates that hundred percent college students use internet starting from daily to at least one time of a month.

It is conjointly found that urban college students use internet over rural college students in terms of daily or $3 / 4$ times of every week as calculated criteria. However, on the opposite hand, it's noted that rural college students are exploitation internet over the urban college students in terms of $3 / 4$ times of a month or just one occasion of a month. After analysis, it's conjointly found that male college students use internet over the feminine college students in terms of daily or $3 / 4$ times of every week. On the opposite facet, feminine college students use internet over male college students in terms of $3 / 4$ times of a month or just one occasion of a month.

The present study indicates that Science college students use internet over the arts college students in terms of daily or $3 / 4$ times of every week. On the other hand humanities college students use internet over science counterpart in terms of $3 / 4$ times of a month or just one occasion of a month as a calculated criteria.

Present study conjointly indicates that Hindu college students use internet over Muslim college students in terms of daily or $3 / 4$ times of every week. However on the opposite facet, it's conjointly found that Muslim college students use internet over Hindu college students in terms of $3 / 4$ times of a month or just one occasion of a month as calculation criteria.

Most of students use internet for social media, news and $20.67 \%$ students using internet for educational information.

On the idea of this analysis work government ought to organized better internet facility in rural and concrete areas and intended the college or school students to most exploitation internet for the aim of education. The internet has emerged because the single most powerful medium for providing access to unlimited data. The internet is associate indivisible a part of today's academic system. The internet facility has enabled the lecturers and also the students to reinforce their educational excellence by providing them the foremost up-to-date data and access to the worldwide data.

\section{Reference:-}

1. Sridevi, S. \& Indrani, T. (2015). A Study on the use of Internet Usage among B.Ed. Students of KSR College of Education - Tiruchengode. International Journal of Advanced Research in Education \& Technology, Vol. 2, Issue 4, ISSN: 2394-2975.

2. Singh, D. (2014). A Systematic Review of Literature on Effect of Internet Use on Students in India. Online International Interdisciplinary Research Journal, Volume-IV, ISSN: 2249-9598.

3. Vidyachathoth, Kodavanji B., Kumar, N.A., and Pai, S.R. (2014). Correlation between Affect and Internet Addiction in Undergraduate Medical Students in Mangalore. J Addict Res Ther 5: 175. doi: 10.4172/21556105.100017

4. Sharma, A., Sahu, R., Kasar, P. K., \& Sharma, R. (2014). Internet Addiction among Professional Courses Students: A Study from Central India. International Journal of Medical Science and Public Health.

5. Manjunatha, S. (2013). The Usage of Social Networking Sites among the College Students in India. International Research Journal of Social Sciences, Vol. 2(5), 15-21, ISSN: 2319-3565.

6. Thanuskodi, S, (2013). "Gender Differences in Internet Usage among College Students: A Comparative Study" Library Philosophy and Practice (e-journal). Paper 1052.http://digitalcommons.unl.edu/libphilprac/1052. 
7. Jackson, L.A., et al. (2011). A longitudinal Study of the Effects of Internet Use and Videogame Playing on Academic Performance and the Roles of Gender, Race and Income in these Relationships. Computer ISM Human Behaviour Vol. 27 no 1, 227-239.

8. Loan, A.F. (2011). Internet Use by Urban and College students: A Comparative Study. Journal of library and information technology, Vol. 31, No. 6, pp. 431-436.

9. Jones, S. (2002). The Internet Goes to College, Internet \& American life [available from http://www.pewinternet.org/.

10. Mishra, O.P., Yadava, N., \& Bisht, K. (2005). Internet Utilization Pattern of Undergraduate Students. University News, 43(13), 8-12.

11. Kumar, R. \& Kaur, A. (2005). Internet and its Use in the Engineering Colleges of Punjab, India: A case study. Webology, 2(4).

12. Mishra, O.P., Yadava, N., \& Bisht, K. (2005). Internet Utilization Pattern of Undergraduate Students. University News, 43(13), 8-12.

13. Ono, H. \& Zavodny, M. (2003). Gender and the Internet. Social Science Quarterly, 84 (1), 111-121.

14. Bimer, B. (2000). Measuring the Gender Gap on the Internet. Social Science Quarterly, 81 (3), $\quad$ 868-876. Data Retrieved from http://www.Personal.si.umich.edu/ rfrost/courses/SI110/readings.DigiDivide/Bimer on DigiDivide.pdf

15. Pai, (2017). http://www.medianama.com/author/vivek/.

16. www.statista.com/topics/2157/internet-usage-in-india. 